\title{
Vocabulary learning strategies among advanced Turkish learners
}

Ioannis Galantomos

Department of Mediterranean Studies, University of the Aegean, Greece

https://doi.org/10.36505/ExLing-2011/04/0018/000187

\begin{abstract}
The goal of this paper is to examine the vocabulary learning strategies used by Turkish learners at an advanced level. Current research suggests that vocabulary is an important component of language proficiency. Nevertheless, for a long period of time it was a neglected aspect during foreign language teaching and learning. Vocabulary learning strategies play a crucial role in vocabulary acquisition. In order to investigate the vocabulary learning strategies used by advanced Turkish learners of Greek origin, we conducted a small-scale experiment. Our results indicate a preference for strategies of formal vocabulary learning and practicing over spontaneous vocabulary learning strategies and self-initiated independent vocabulary learning.
\end{abstract}

Key words: foreign language learning, Turkish as a foreign language

\section{Introduction}

During the past decades, vocabulary has been a neglected aspect in the field of foreign language learning (Meara 1980). Nevertheless, current research has demonstrated the important role vocabulary plays in the acquisition of a foreign language (e.g. Meara 2002). Moreover, the above mentioned neglect opposes to the importance attributed to vocabulary by learners themselves (Meara 1980).

One of the aspects that have attracted research attention is the study of the strategies that learners use in order to cope with the meanings of new words. Early research into learners' strategies began in the 1970s and by the 1990s the interest has moved to vocabulary learning strategies (Schmitt 2010). Experiments carried out so far reveal that learners use many strategies when they encounter unknown words. This finding is due to the fact that learners find it more feasible and manageable to deal with individual lexical items rather than with larger units (Schmitt 2010).

The increasing interest in vocabulary learning strategies is also reflected in the various taxonomies that have been proposed in the relevant literature (for a review cf. Pavičíakač2008). For instance, Schmitt (1997) indentified four major groups of strategies, namely, social (=cooperation with other learners), cognitive (=language manipulation or transformation), metacognitive (control of the learning process) and memory (=relating a new word with existing knowledge) strategies. Later, this classification was enriched with determination strategies (=discovering a new word's meaning

ExLing 2011: Proceedings of 4th Tutorial and Research Workshop on Experimental Linguistics, 25-27 May, Paris, France 
without the involvement of other learners or speakers). Another influential taxonomy is the one proposed by Nation (2001) and according to which three general classes of strategies are introduced, namely, planning (choosing what to focus on and when to focus on), sources (=finding clues about new words) and processes (=establishing knowledge).

In view of the above, we carried out a small-scale experiment in order to investigate the vocabulary learning strategies used by advanced Turkish learners.

\section{Method \\ Participants}

Our study consisted of 22 tertiary Greek students who learn Turkish as a foreign language in the Department of Mediterranean Studies at the University of the Aegean (Rhodes island campus). Regarding our participants' sex, 4 were males and 18 females. Their mid age was 22.7 years old and they were all attending regular Turkish classes at an advanced level $\left(3^{\text {rd }}\right.$ level according to department's terminology).

\section{Instrument}

The data on vocabulary learning strategies were collected through adopting and adapting an existing questionnaire consisting of 27 vocabulary learning strategies (the questionnaire is available upon request). This questionnaire has already been used in a similar survey (Pavičić Takač 2008). These 27 strategies are categorized into three main groups, namely, strategies of formal vocabulary learning and practicing, self-initiated independent vocabulary learning and spontaneous vocabulary learning. According to this scheme, strategies 1-11 fall within the first group, strategies 12-20 fall within the second group and the remaining ones (i.e. 21-27) within the third group. Each strategy is followed by a three-type scale (i.e. 1: never, 2: sometimes and 3: always).

\section{Procedure}

The questionnaire was administered to all students enrolled on advanced Turkish classes in January 2011. The researcher, after being introduced by the instructor, explained the goal of the study and provided detailed instructions on how to fill out the above mentioned questionnaire. The whole procedure lasted for approximately 25 minutes. The data were analysed by means of SPSS for Windows and the statistical criterion $\mathrm{x}^{2}(\mathrm{p}<0.05)$ was used to examine the statistical significance of our findings.

\section{Results}

Our results indicate a preference for strategies of formal vocabulary learning and practicing over the other two types of strategies. In particular, our 
participants used more strategies of the first group ( 7 out of $11, p<0,05)$. On the other hand, only 4 and 2 strategies of the second and third group of strategies respectively showed a statistical significance $(p<0,05)$.

\section{Discussion}

Our findings (i.e. preference for formal vocabulary learning strategies) can be attributed to the context of learning Turkish. Formal learning strategies in general are employed in a classroom-based setting. Turkish is learnt by our participants as a foreign (and not as a second) language, that is, there is no real and actual need for communication in the target language outside classroom. According to Pavičić Takač, (2008), reliance on formal vocabulary learning strategies involves instrumental motivation and is oriented towards formal language learning tasks. For instance, our participants' reports that they test themselves (strategy 4), make lists of new words (strategy 9) and translate new lexical items into their mother tongue (strategy 11) are related to the fact that they expect to be tested and evaluated for their knowledge of Turkish language by their instructors in the form of, lets say, a final exam. Therefore, the fact that they showed a preference for formal vocabulary learning strategies over more functional (/communicative) strategies is due to the requirements and norms of instructed language learning.

Experimental data support our finding. Thus, Lamb (2004) suggests that the degree of exposure to the target language can have an impact on the development of more or less and specific vocabulary learning strategies. In addition, Pavičić Takač (2008) reports that the major difference observed between the two groups which participated in her study is related to the large amount of language input.

Moreover, the preference for formal vocabulary learning strategies may be related to the sex factor. The majority of our sample consisted of females. Research data (e.g. Jiménez Catalán 2003) suggest that females rely more often on formal rule strategies than males. This finding is corroborated by $\mathrm{Gu}$ (2002) who claims that females tend to use more strategies that contribute to success in EFL learning. Nevertheless, the limited sample of our survey and the lack of equivalence between the two sexes do not allow us to reach final conclusions regarding this aspect.

\section{Conclusions}

To sum up, the results of our survey reveal a preference of our subjects for formal vocabulary learning strategies over more functional ones. This finding is attributed to the classroom-based context of learning the target language and it can probably be related to sex differences, although more experimental data are required in order to support such a claim. 


\section{$78 \quad$ I. Galantomos}

\section{References}

Gu, Y. 2002. Gender, Academic Major, and Vocabulary Learning Strategies of Chinese Efl Learners. RELC Journal, 33, 35-54.

Jiménez Catalán, R. 2003. Sex differences in L2 vocabulary learning strategies. International Journal of Applied Linguistics, 13, 54-77.

Lamb, M. 2004. It depends on the students themselves': Independent language learning at an Indonesian state school. Language, Culture and Curriculum, 17, 229-245.

Meara, P. 1980. Vocabulary Acquisition: A Neglected Aspect of Language Learning. Language Teaching and Linguistics: Abstracts, 13, 221-246.

Meara, P. 2002. The rediscovery of vocabulary. Second Language Research, 18, 393-407.

Nation, I.S.P. 2001. Learning Vocabulary in Another Language. Cambridge: CUP.

Pavičić Takač, V. 2008. Vocabulary Learning Strategies and Foreign Language Acqusition. Clevendon: Multilingual Matters.

Schmitt, N. 1997. Vocabulary learning strategies. In Schmitt, N. and McCarthy, M. (eds.) 1997, Vocabulary: Description, Acquisition and Pedagogy, 198-227. Cambridge: CUP.

Schmitt, N. 2010. Researching Vocabulary. A Vocabulary Research Manual. London: Palgrave Macmillan. 